\title{
A new role of proficiency testing in nuclear analytical work
}

\author{
Heydorn, Kaj
}

Published in:

Nuclear Proficiency Testing

Publication date:

2008

Document Version

Early version, also known as pre-print

Link back to DTU Orbit

Citation (APA):

Heydorn, K. (2008). A new role of proficiency testing in nuclear analytical work. In Nuclear Proficiency Testing: Proceedings of the 1st International Workshop (1036 ed., pp. 38-46). American Institute of Physics. AlP Conference Proceedings No. 1036

\section{General rights}

Copyright and moral rights for the publications made accessible in the public portal are retained by the authors and/or other copyright owners and it is a condition of accessing publications that users recognise and abide by the legal requirements associated with these rights.

- Users may download and print one copy of any publication from the public portal for the purpose of private study or research.

- You may not further distribute the material or use it for any profit-making activity or commercial gain

- You may freely distribute the URL identifying the publication in the public portal

If you believe that this document breaches copyright please contact us providing details, and we will remove access to the work immediately and investigate your claim. 


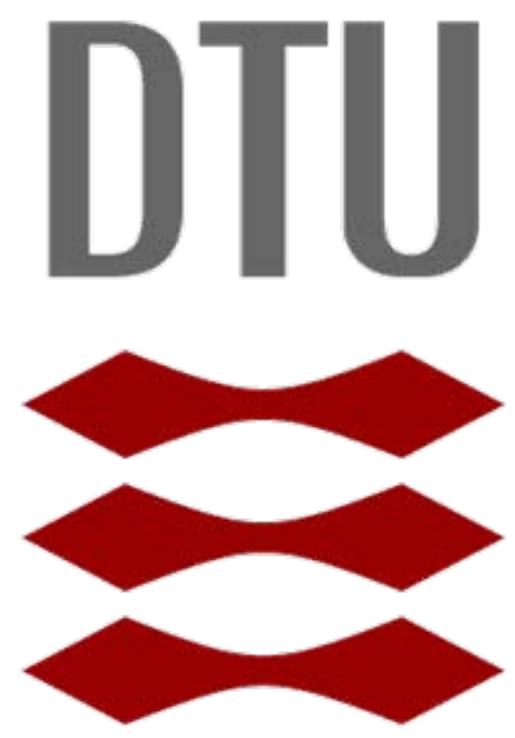




\section{A new role of Proficiency Testing in Nuclear Analytical Work}

Kaj Heydorn

Technical University of Denmark 
In the beginning was the word............. (Joh.1:1)

\section{and the word was uncertainty}

- but some people did not like it, and

- those who did could not use it, because we were not sure of its meaning 


\title{
International Vocabulary of Basic and General Terms in Metrology
}

\author{
VIM \\ 2nd Edition \\ 1993
}

Technical University of Denmark 


\section{1. axiom}

- A result without statement of uncertainty is useless

because no valid conclusions can be reached 


\title{
Guide to the Expression of Uncertainty in Measurement
}

GUM

\author{
1st Edition
}

1995 


\section{Evaluation of \\ Sampling Uncertainty}

- Type A

statistical analysis of actual observations

- Type B

any other method

Technical University of Denmark 


\section{2. axiom}

- A result

with an incorrect statement of

uncertainty

is dangerous

because erroneous conclusions may

be reached

Technical University of Denmark 


\title{
Accreditation after ISO 17025*
}

- Correct measurement results:

- no significant bias

- reliable uncertainty

\author{
*or ISO 15189
}




\section{Proficiency Testing}

ISO 13528:

Statistical methods for use in proficiency testing by interlaboratory comparisons

\section{Laboratory Bias}




\section{International Vocabulary of Basic and General Terms in Metrology}

VIM

3rd Edition

2007 


\section{Measurand}

\section{quantity intended to be measured}

- this definition differs from VIM 2

- must include exact specifications 


\section{Definition of the Measurand I}

- The determinand, i.e.

the chemical species to be determined

- The specified amount of material to which the measurement should apply 


\section{Quantity value}

\section{Magnitude of a quantity}

expressed as a product of

a number and a unit

Technical University of Denmark 


\section{Measurement Result}

\section{Information on the measurand consisting of}

- a single quantity value, $\boldsymbol{y}$ and

- a measurement uncertainty, u 


\section{Definition of the Measurand II}

- A result without corresponding

definition of the measurand is worthless

- An uncertainty without corresponding specification of the measurand is misleading 


\section{Initial proficiency requirements I}

1) Definition of the measurand, incl. identification of the determinand and specification of the system

2) Choice of analytical measurement method and detailing a procedure yielding traceable results

3) Development of an uncertainty budget, including correct application of counting statistics

4) Partial verification of uncertainty budget by replicate analyses 


\section{Final proficiency requirements II}

5) Choice of sampling strategy and number of samples to be analyzed

6) Reporting results of analyses corrected for bias and with specified coverage interval.

7) Final verification of analytical results and their uncertainties by proficiency testing

8) Calculation of the $E_{n}$ number 


\section{Our null hypothesis is now that}

All reported measurement results for proficiency testing comply with these stipulations, so that

traceability is consistent with the definition of the measurand

all known biases have been corrected for

uncertainties are based on a verified uncertainty budget with a large number of effective degrees of freedom 


\section{Bayesian estimate of mean}

$$
\hat{\mu}=\frac{\sum_{i} \omega_{i} \cdot y_{i}}{\sum_{i} \omega_{i}}
$$

where $\omega_{i}=u_{i}^{-2}$ and $u_{\mu}=\sqrt{\frac{1}{\sum_{i} \omega_{i}}}$

Technical University of Denmark 


\section{Test statistic}

$$
T=\sum_{i} \frac{\left(y_{i}-\hat{\mu}\right)^{2}}{u_{i}^{2}}
$$

Chi-square distribution with n-1 degrees of freedom 


\section{$E_{n}$ numbers}

$E_{n}^{(i)}=\frac{y_{i}-\hat{\mu}}{\sqrt{U_{i}^{2}+U_{\mu}^{2}}}$

$U \sim 2 u$

Technical University of Denmark 


\section{"bottom up" strategy}

a) expanded uncertainties, $U$, are converted to standard uncertainties, $u=U / k$

b) measurement results are ordered according to decreasing $u$

c) results are added in this order one at a time, and a value of $T$ is calculated

d) if $T \leq \chi 2_{\alpha, m-1}$ the next measurement result is added 


\section{"bottom up" strategy}

e) if $T>\chi 2_{\alpha, m-1}$ the result with the largest contribution to $T$ is removed

f) after reaching the end of the list go back to $c$ ) and add results previously removed

g) repeat c) to f) until there is no change in the selected group of measurement results

h) calculate the reference value $\mu$ and its uncertainty $u_{\mu}$ 


\section{"top down" strategy}

a) apply robust algorithms $A$ and $S$ [3] to the $y_{i}$ data for estimating $\mu$, respectively their uncertainties $U_{i}$ for estimating $U_{\mu}$

b) calculate $E_{n}$ numbers and disregard all results with $\left|E_{n}\right|>1$,

c) calculate the weighted mean of the remaining results, using $1 / U_{i}^{2}$ as weights 


\section{"top down" strategy}

d) calculate its corresponding uncertainty from

$$
U_{\mu}^{-2}=\sum U_{i}^{-2}
$$

e) repeat b) to d) until there is no change in the selected group of measurement results

f) use their weighted mean as reference value and $U_{\mu}$ as its expanded uncertainty. 


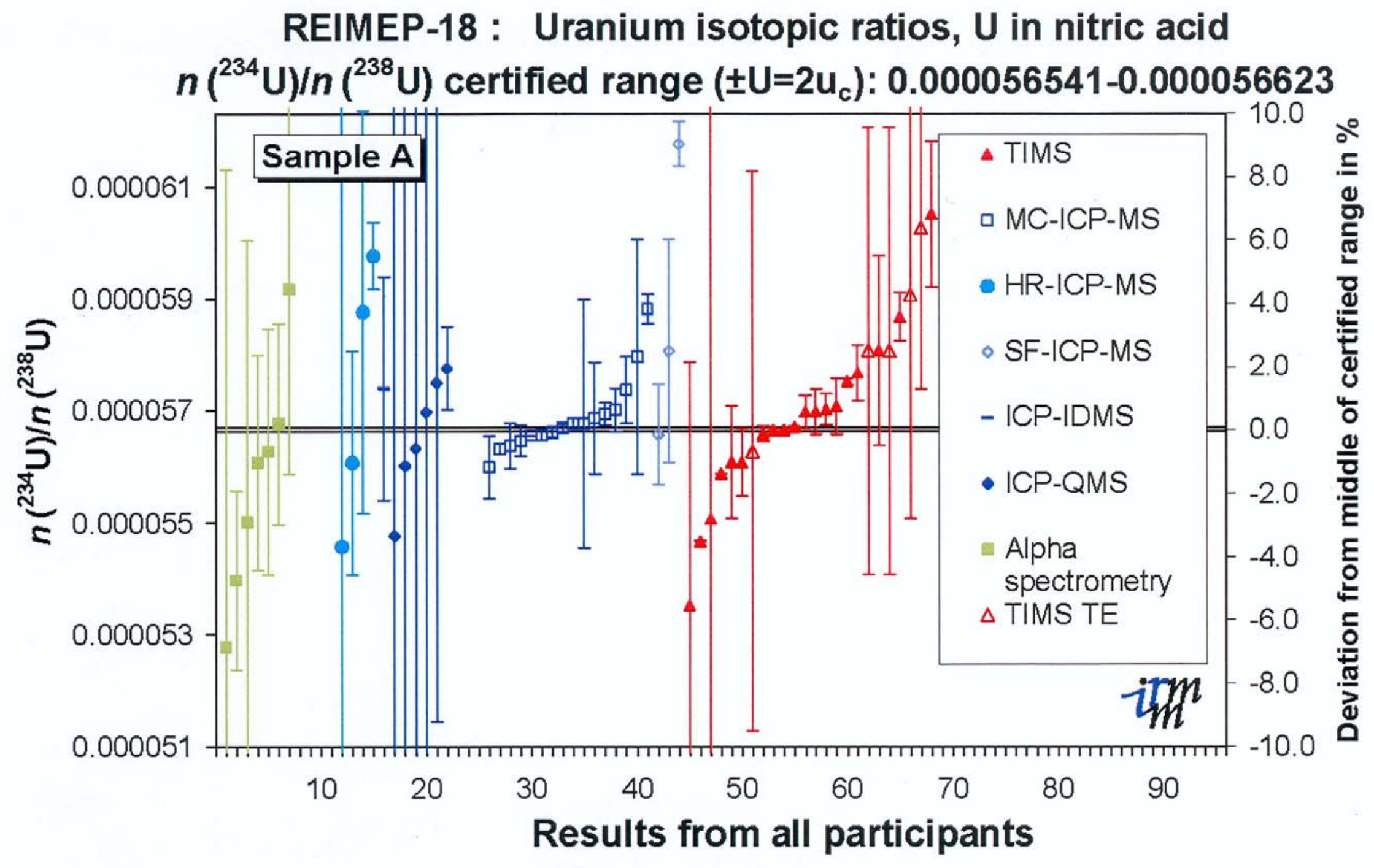

Results for the $n\left({ }^{234} \mathrm{U}\right) / n\left({ }^{238} \mathrm{U}\right)$ ratio for REIMEP $18 \mathrm{~A}$ 


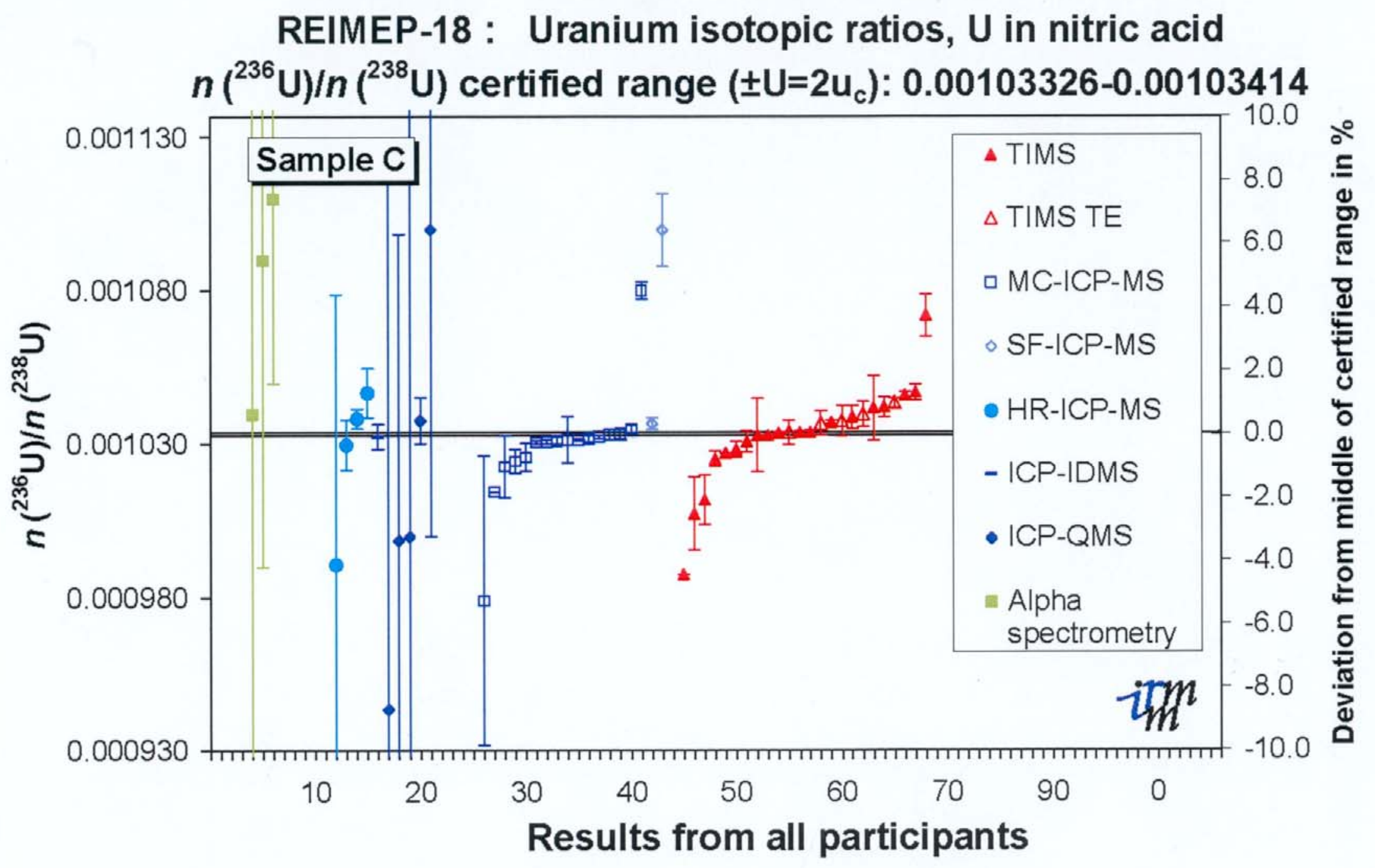

Results for the $n\left({ }^{236} \mathrm{U}\right) / n\left({ }^{238} \mathrm{U}\right)$ ratio for REIMEP $18 \mathrm{C}$ 


\section{Reference values for Uranium isotopic ratios}

\begin{tabular}{|l|c|c|c|c|}
\hline \multicolumn{1}{|c|}{ Strategy } & $\begin{array}{c}\left.{ }^{234} \mathrm{U}\right|^{238} \mathrm{U} \text { value } \\
\pm \text { Uncertainty (k=2) }\end{array}$ & $\begin{array}{c}\text { Results } \\
\text { accepted }\end{array}$ & $\begin{array}{c}{ }^{236} \mathrm{U} /{ }^{238} \mathrm{U} \text { value } \\
\pm \text { Uncertainty (k=2) }\end{array}$ & $\begin{array}{c}\text { Results } \\
\text { accepted }\end{array}$ \\
\hline Bottom up & $0.000056581 \pm 31$ & 42 & $0.00103368 \pm 51$ & 27 \\
\hline Top down & $0.000056609 \pm 37$ & 39 & $0.00103390 \pm 54$ & 25 \\
\hline Combined & $0.000056581 \pm 31$ & 42 & $0.00103368 \pm 51$ & 27 \\
\hline
\end{tabular}




\section{Correct measurement results}

- Participants

- Methods

Technical University of Denmark 


\section{${ }^{234} \mathrm{U} /{ }^{238} \mathrm{U}$ proficiency data}

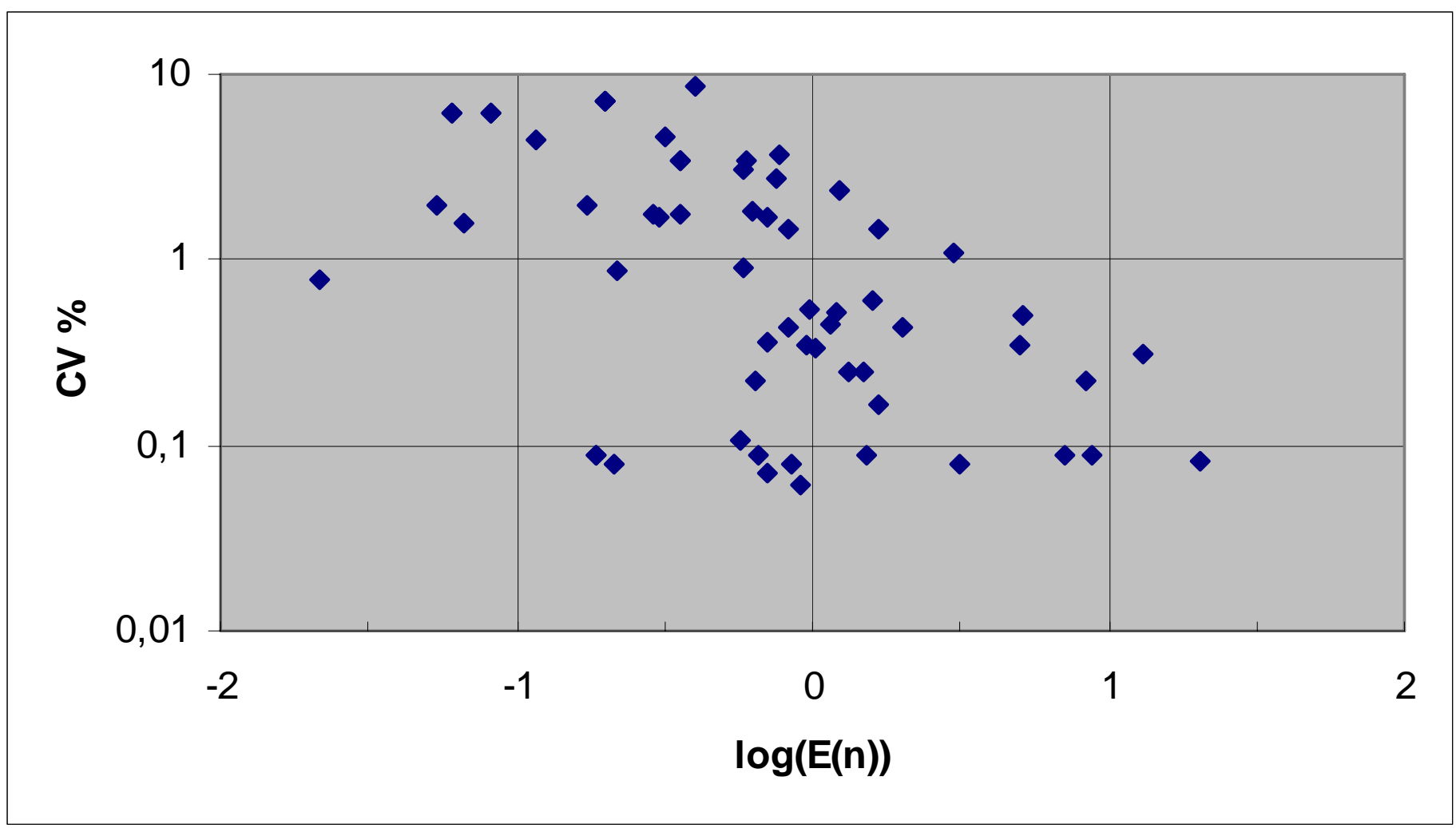

Technical University of Denmark 


\section{${ }^{236} \mathrm{U} /{ }^{238} \mathrm{U}$ proficiency data}

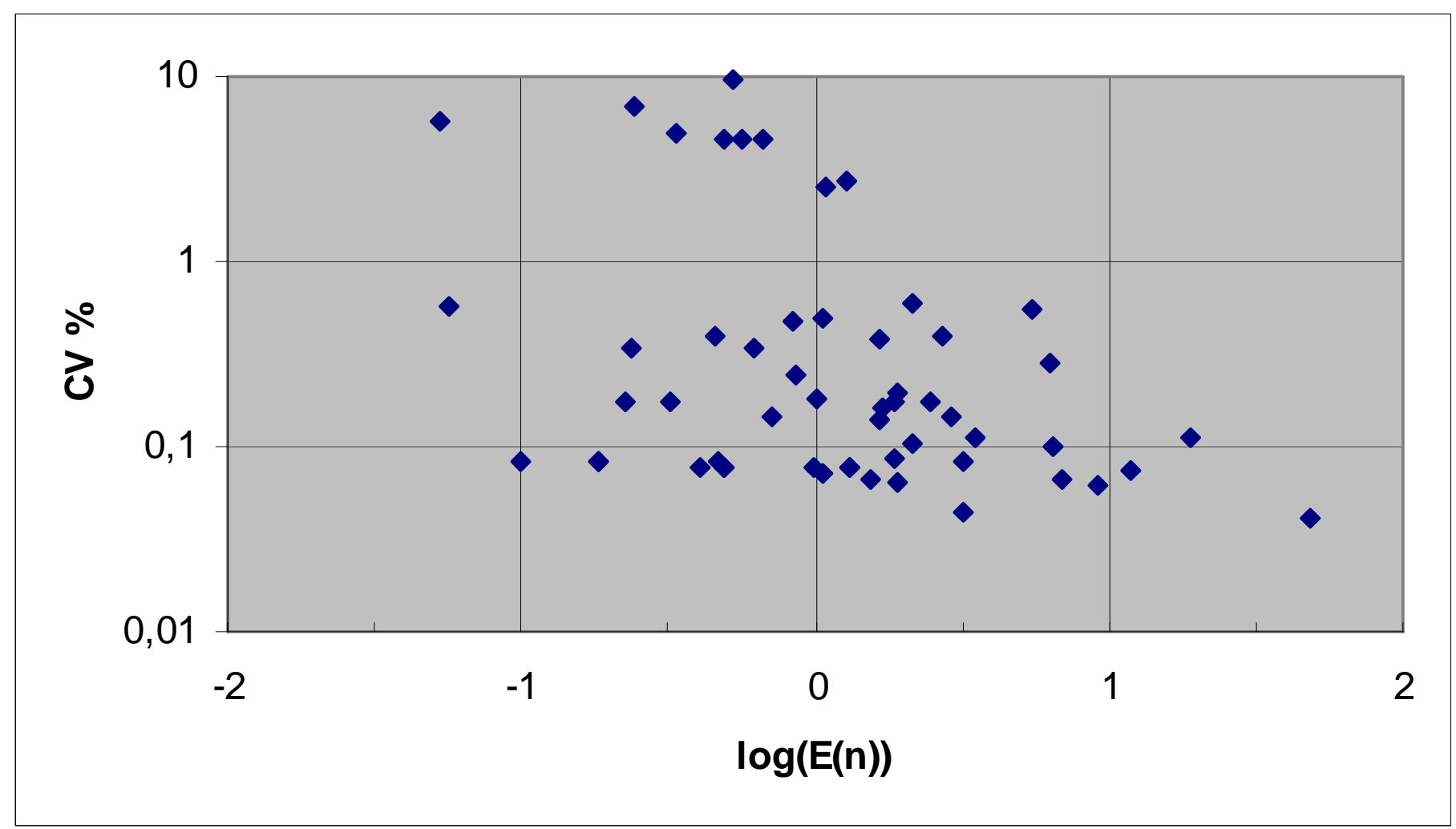

Technical University of Denmark 


\section{Median of $E_{n}$ numbers for analytical methods}

$\begin{array}{lcccc}\text { Technique } & \begin{array}{c}\text { Sample A } \\ \text { Median }\end{array} & \begin{array}{c}\text { Number } \\ \text { results }\end{array} & \begin{array}{c}\text { Sample C } \\ \text { Median }\end{array} & \begin{array}{c}\text { Number } \\ \text { results }\end{array} \\ \text { Alpha } & -0,31 & 7 & 0,56 & 3 \\ \text { HR-ICP } & 0,20 & 4 & 0,59 & 4 \\ \text { ICP-IDMS } & 0,36 & 1 & -0,32 & 1 \\ \text { ICP-QMS } & -0,01 & 6 & -0,24 & 5 \\ \text { MC-ICP } & 0,14 & 16 & -1,06 & 16 \\ \text { SF-ICP } & 0,71 & 3 & 3,70 & 2 \\ \text { TE } & 0,35 & 5 & 1,45 & 4 \\ \text { TIMS } & 0,66 & 19 & 0,34 & 20\end{array}$




\section{VIM 3 is a major challenge in}

- Our way of interpreting analytical data Co-operate with the client to define

fitness for purpose

- Our way of treating proficiency data Accreditation authorities beware of

the uncertainty of assigned values 
Technical University of Denmark

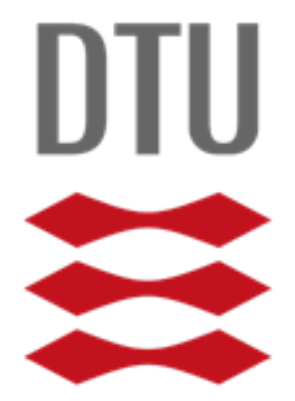




\section{Question from the audience:}

- Would the proposed method lead to substantially different $E_{n}$ numbers?

- Not for the particular example used here, but for the example used in ISO 13528 the drastic reduction of the uncertainty of the reference value greatly increases the detection capability for too optimistic reported uncertainties. 


\section{Comparison with certified values}

\begin{tabular}{|c|c|c|c|c|}
\hline Value & $\begin{array}{c}{ }^{234} \mathrm{U} /{ }^{238} \mathrm{U} \text { value } \\
\pm \text { Uncertainty (k=2) }\end{array}$ & $\begin{array}{c}\text { Results } \\
\text { accepted }\end{array}$ & $\begin{array}{c}{ }^{236} \mathrm{U} /{ }^{238} \mathrm{U} \text { value } \\
\pm \text { Uncertainty }(\mathrm{k}=2)\end{array}$ & $\begin{array}{c}\text { Results } \\
\text { accepted }\end{array}$ \\
\hline Reference & $0.000056581 \pm 31$ & 42 & $0.00103368 \pm 51$ & 27 \\
\hline & & & & \\
\hline Certified & $0.000056582 \pm 41$ & Sample A & $0.00103370 \pm 44$ & Sample C \\
\hline
\end{tabular}




\section{Reference values* for $\mathrm{Pb}$ in IMEP-9}

\begin{tabular}{cccc}
\hline Method & $\begin{array}{c}\text { Reference value } \\
\pm \text { Uncertainty }\end{array}$ & $\begin{array}{c}\text { Number of } \\
\text { accepted results }\end{array}$ & Comment \\
\hline Synthesis of Precision & $617.7 \pm 2.7$ & 60 & Recommended \\
$E_{n}$ numbers & $614.1 \pm 3.2$ & 59 & Alternative \\
Robust average & $605 \pm 26$ & 181 & ISO 13528 (2005) \\
ICP-MS & $623 \pm 13$ & 6 & Certified value \\
\hline
\end{tabular}

*in units of $10^{-10} \mathrm{~mol} / \mathrm{L}$ 